\title{
A Framework for Automatic Identification of Learning Styles in Learning Management Systems
}

\author{
Ignacio Núñez Márquez, Luis-Felipe Rodríguez, Guillermo Salazar Lugo, \\ Luis A. Castro, Manuel Domitsu Kono \\ Instituto Tecnológico de Sonora, Department of Computer and Design, \\ Mexico \\ ignacio_nmarquez@hotmail.com, \{luis.rodriguez, gsalazar47040, \\ luis.caztro, manuel.domitsu\}@itson.edu.mx
}

\begin{abstract}
A current concern of modern societies is the quality of their educational systems. Learning Management Systems (LMSs) are technological tools that have been used to improve and extend the traditional educational system. Although LMSs have greatly benefited from technological advances, this type of educational platforms are still in need of mechanisms to provide virtual educational environments in which students are considered the main actor in the design of the learning process, thus contributing to increase the quality of educational systems. In particular, LMSs usually lack mechanisms for recognizing users' learning styles, which describe the way a learner acquires and process information. In this work we propose a framework for automatic identification of learning styles in LMSs and present a specific implementation. A key goal of the framework design is to provide researchers and practitioners with a tool that facilitates the specification of expert knowledge for classifying students with respect to their learning styles in LMSs.
\end{abstract}

Keywords: Learning style, LMS, automatic identification, framework.

\section{Introduction}

Education is a key aspect associated to the development of a country. The knowledge acquired by individuals in educational institutions impact on a country's capability for doing research, innovation and technological development as well as on its economic growth [14]. Educational systems are therefore designed to facilitate individuals with access to education and to allow them to acquire abilities and knowledge that can contribute to their own personal and academic development and to the progress of their countries [2]. Moreover, a crucial concern of modern societies is the quality of educational systems. This desire for quality in education becomes a challenge as educational systems are mainly based on traditional models that consider the instructor as the main actor, minimizing the role of students as individuals with particular needs and ways of learning. 
This situation has motivated researchers to find novel strategies and methods aimed at promoting the quality of educational systems [15]. For example, the availability of mobile devices that can access the Internet and the institutions' technological infrastructure has open avenues for novel designs of educational methods based on online learning, social networking tools, and intelligent classrooms $[1,13]$. In particular, LMSs are tools that have greatly benefited from technological advances and have become a mechanism for improving and extending traditional educational systems $[1,16,17]$. LMS are technological tools that enable the creation of virtual learning environments that include components for adding and displaying academic material (e.g., lectures, exercises and tests), communication, defining sequences of activities, among other things. LMSs also include mechanisms to monitor learners' academic behavior and to make these data available to teachers in order to mediate the learning process.

Although LMSs have taken advantage of technology to manage various types of content (e.g., multimedia), to offer a diversity of communication mechanisms, complex graphics and efficient user-behavior tracking mechanisms, LMSs are still in need of mechanisms to provide virtual educational environments in which learners are considered the main actors in the design of their learning process, thus contributing to increase the quality of educational systems $[8,16]$. This concern becomes crucial in the academic development of the individual as it has been recognized that learners have differences in how they acquire and process information $[5,10]$. There are several ways for involving learners in the design of their learning process. For example, monitoring learners' academic performance and emotions may inform how learners perceive their learning process and help to infer their academic interests. Ultimately, this information becomes useful to personalize the user's learning environment in a LMS. Although several efforts have been reported in the literature, these proposals are usually designed and developed for very specific academic purposes and validated in very controlled environments $[7,11]$. The redesign and implementation of these kinds of proposals in LMSs such as Moodle and Chamilo would require considerable effort.

In this paper, we propose a framework for automatic identification of learning styles in LMSs such as Moodle. A key goal of the framework design is providing researchers and practitioners in the field of education with a tool that facilitates the specification of expert knowledge for classifying students with respect to their learning styles in educational platforms. We also present an implementation of the framework, which takes advantage of theories and models of learning styles reported in psychology and education literature, techniques from the field of Artificial Intelligence (AI), and advances in technologies for distributed systems. The proposed framework is not intended to define a mechanism to automatically identify users' learning styles with a minimal classification error. Instead, the presented framework attempts to serve as a guideline for the generation of virtual learning environments that take advantage of existing technologies and related literature for the automatic identification of users' learning styles in LMSs. 


\section{Related Work}

User-centered learning environments aim at minimizing the weaknesses of traditional educational systems that follow the "One-Size-Fits-All" model [9]. Personalized learning environments are designed to involve learners in the design of their own learning process and allow them to set their own goals for learning. In these types of environments, learners progress at their own pace and are supported to reach their maximum potential by providing access to a wide range of academic material and teaching strategies, according to learners' strengths and weaknesses, and academic and personal interests [4]. A personalized learning environment consists of two phases:

1. Understand learners" "situation" in terms of aspects such as their cognitive and affective state, previous knowledge, abilities, personal and academic interests, and learning style.

2. Once learners' "situation" is known, it is necessary to personalize students' learning environment.

It has been recognized that individuals have preferences regarding the type of content they use for learning [5,10]. For example, some students prefer watching videos rather than reading lectures. A key indicator that describes users' preferences is their learning style. In general, the learning style is the way individuals learn [7]. Learning styles allow classifying learners' behavior according to how they take the information, how they form strategies to learn, how they understand new concepts, and how they analyze information used to learn a particular knowledge. The literature reports several studies about learning styles in which learners are usually classified according to a series of categories. For example:

- Felder and Silverman [5] explain students' learning preferences based on four dimensions: active and reflexive learners; sensing and intuitive learners; visual and verbal learners; and sequential and global learners;

- Kolb [10] propose a model to explain learning styles that is based on four categories: Diverging, Assimilating, Converging, and Accommodating.

LMSs like Moodle aim at supporting teachers in creating and managing courses and provide them with a great variety of features that can be included in a course, such as learning material, quizzes, discussion forums, and assignments. Moreover, these types of LMSs provide a set of features to support teachers in the construction, administration and management of courses. Most LMSs treat all learners equally, regardless of their learning style preferences [8,16]. Recognizing users' learning styles may bring many benefits in LMSs. In LMSs like Moodle and Chamilo, understanding how a student learns makes it possible to personalize the virtual learning environment by determining which elements comprise such learning environment, including teaching strategies, academic material, learning activities, feedback strategies, and communication strategies. Although most LMSs provide educators, administrators and learners mechanisms for personalizing the learning environment, this personalizing process must be carried out by the instructor, meaning it does not occur automatically. 
The literature reports various attempts to create computer systems that help with the automatic identification of users' learning styles $[7,8]$. The traditional way is based on the use of questionnaires that learners fill out. However, this strategy has been criticized as questionnaires usually include more than 100 items, making it tedious for learners to answer the questions or inducing learners to answer them arbitrarily. The automatic identification approach consists on monitoring learners' behavior and building a user model that describes their preferences. A model for learner classification is then built based on the user model and the results of applying a learning style instrument to a group of initial learners. This model is then used to automatically classify learners on the basis of their behavior and without the need to answer the questionnaire [7].

Although current technology has enabled the construction of highly complex educational platforms that may help users learn different things, mechanisms for automatically identifying users' learning styles in these platforms are still to be developed. Moreover, most efforts for automatic identification of learning styles are developed as prototypes that are validated in very controlled environments [7], making them unsuitable for their use in LMSs like Moodle.

\section{Proposed Framework}

In this section we present a framework that endows LMSs with mechanisms to automatically identify users' learning style. The framework is designed to take advantage of complex characteristics offered by existing LMSs such as Moodle, which are tools that have greatly benefited from technological advances.

The idea behind this proposal is to provide a computer-based service that classifies users of LMSs with respect to their learning style. A key assumption in the design of this computer-based service is that the behavior of LMS' users can be analyzed on the basis of expert knowledge drawn from theories of learning styles reported in psychology and education literature. In particular, this computer-based service is designed to identify users' learning styles taking into account the following two types of information:

1. User behavior in a LMS: The framework is designed to take into account the information a LMS is able to monitor about users' behavior and that is useful for classifying their learning styles, such as courses completed, activities initiated and completed, resources visited, test results, the use of forums and chats, pages accessed and the time and date learners accessed them, and the type of content revised by learners such as text, images or videos.

2. Expert knowledge about learning style models: The framework uses expert knowledge in the classification process. It is designed to take advantage of existing theories and models that explain how learners can be classified in a variety of categories according to how they take in and process information. This knowledge may be represented by experts in a variety of ways (e.g., in the form of simple IF-THEN rules). 


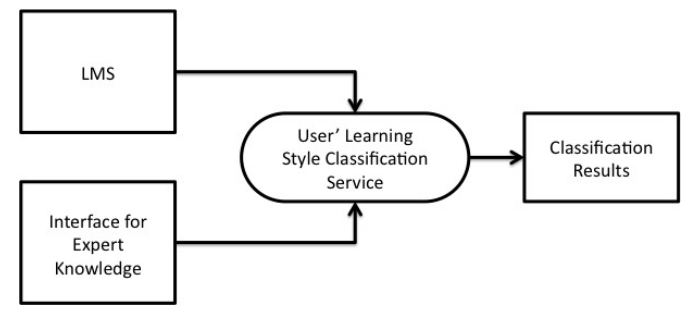

Fig. 1. Framework for the automatic identification of users' learning styles in LMSs.

Figure 1 presents the main components included in the framework and their interrelation: LMS, Interface for Expert Knowledge, User's Learning Style Classification Service, and Classification Results. The data flow between these components is as follows. The User's Learning Style Classification Service component is responsible for the classification of users' according to their learning style. This component receives data from the $L M S$ and Interface for Expert Knowledge components. The $L M S$ component sends information about users' behavior within an educational platform. This information is then analyzed on the basis of information sent from the Interface for Expert Knowledge. This last component allows human experts to indicate how the behavior of a learner (within the context of a particular LMS) should be analyzed in order to infer the student's learning style. It is important to note that the framework design recognizes that LMS differ in the type of information they are able to monitor and that the representation of expert knowledge may be based on a variety of learning style models. Finally, the User's Learning Style Classification Service component sends the classification results to the Classification Results component, which presents information about the classification process and the preferences of learners based on their specific learning style. The results presented by these components can be then used to personalize the virtual learning environment in LMSs.

\section{An Implementation of the Proposed Framework}

As previously mentioned, one of the main objectives of the proposed framework is to take advantage of existing LMSs. We believe that these are tools that have greatly benefited from technological developments and that have proven useful in the education domain. In this sense, the $L M S$ component included in the framework can be replaced by any LMS. For example, Moodle provides mechanisms to generate reports of learners' activities, such as resources visited, test results, and the use of forums and chats. All these data becomes useful for identifying user preferences and interests. Moreover, it is possible to add additional features and functionality to Moodle via plugins, which can be developed to automatically monitor and send data to the classification component.

According to the proposed framework, models of learning styles reported in the literature are useful to define how to analyze the information monitored 
in a LMS like Moodle. In Section 2, we mentioned the models proposed by Felder and Silverman [5] and Kolb [10]. In general, all models classify students according to a series of categories that explain how learners acquire and process information. These models include a test or questionnaire to identify students' learning styles. More importantly, these models provide explanations of learners' academic behavior and preferences. As shown in Table 1, descriptions provided by models can be represented in terms of IF-THEN rules. A rule can be defined for a visual learner: IF the learner usually visit resources of type pictures AND the learner usually describe activities using diagrams THEN the learner tends to be VISUAL. Similarly, IF-THEN rules can be defined to determine users' learning styles based on their behavior. The Interface for Expert Knowledge can then be designed to introduce expert knowledge in terms of rules. Moreover, an implementation of the User's Learning Style Classification Service component may take advantage of these rules for classifying the data sent from the $L M S$.

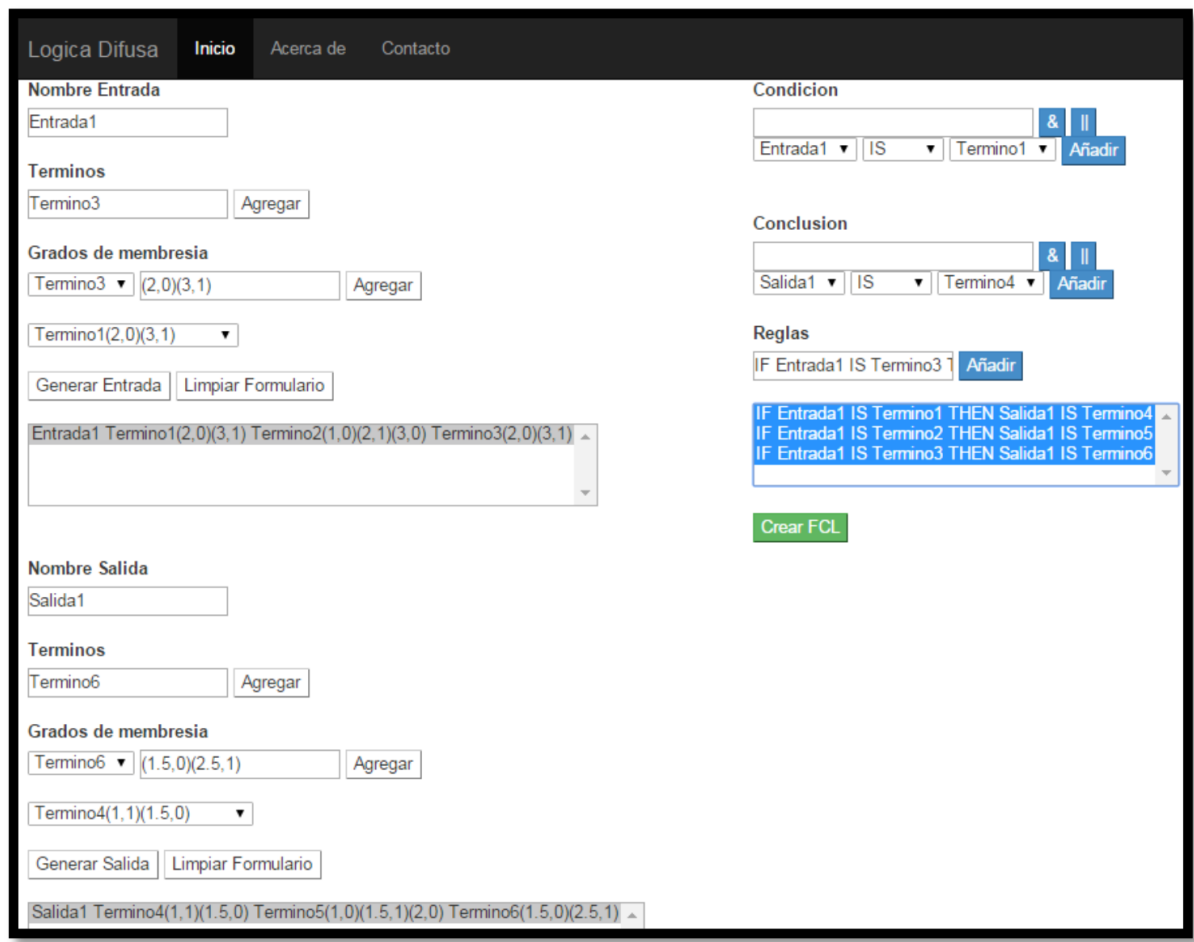

Fig. 2. Interface implemented to introduce Expert Knowledge.

We used Fuzzy Classification to implement the User's Learning Style Classification Service component. Fuzzy Classification is based on the theory of fuzzy sets and fuzzy logic. This type of classification assigns learners into a fuzzy 


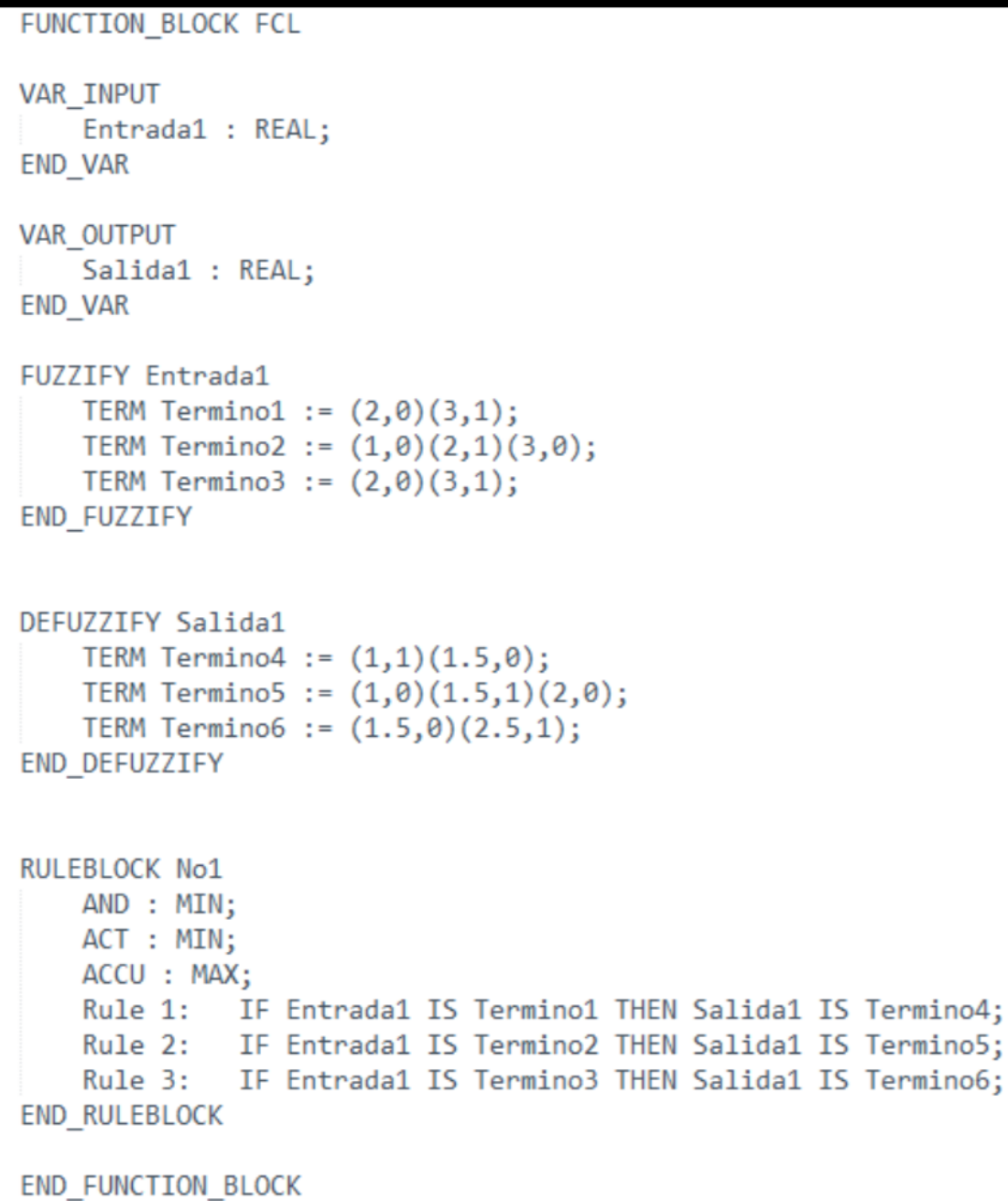

Fig. 3. An example of a FCL file.

set. Importantly, rule-based fuzzy classifiers may be constructed by specifying classification rules as those described in the previous paragraph. A more detailed description of Fuzzy classification is out of the scope of this paper (see [12]).

We used the jFuzzyLogic library [3] to implement fuzzy classification in the User's Learning Style Classification Service component. This library is written in Java and implements the Fuzzy Control Language (FCL). In jFuzzyLogic, all necessary information for the classification task is included in a FCL file: linguistic variables (used to represent variables that describe user behaviors and output variables that represent learning style categories), linguistic terms, 
Table 1. Learning style categories and their descriptions (Felder and Soloman [6]).

\begin{tabular}{|l|l|l|}
\hline $\begin{array}{l}\text { Active and re- } \\
\text { flexive learn- } \\
\text { ers }\end{array}$ & $\begin{array}{l}\text { Active learners tend to retain and understand information best by doing } \\
\text { something active with it-discussing or applying it or explaining it to } \\
\text { others. Reflective learners prefer to think about it quietly first }\end{array}$ \\
\hline $\begin{array}{l}\text { Sensing and } \\
\text { intuitive } \\
\text { learners }\end{array}$ & $\begin{array}{l}\text { Sensing learners tend to like learning facts and often like solving } \\
\text { problems by well-established methods and dislike complications and } \\
\text { surprises. Intuitive learners often prefer discovering possibilities and } \\
\text { relationships, they like innovation and dislike repetition. }\end{array}$ \\
\hline $\begin{array}{l}\text { Visual } \\
\text { and verbal } \\
\text { learners }\end{array}$ & $\begin{array}{l}\text { Visual learners remember best what they see (pictures, diagrams, flow } \\
\text { charts, time lines, films, and demonstrations). Verbal learners get more } \\
\text { out of words (written and spoken explanations). }\end{array}$ \\
\hline $\begin{array}{l}\text { Sequential } \\
\text { and global } \\
\text { learners }\end{array}$ & $\begin{array}{l}\text { Sequential learners tend to gain understanding in linear steps, with } \\
\text { each step following logically from the previous one. Global learners tend } \\
\text { to learn in large jumps, absorbing material almost randomly without } \\
\text { seeing connections, and then suddenly "getting it" }\end{array}$ \\
\hline
\end{tabular}

membership functions (to express in which degree a leaner belongs to a given Fuzzy subset), linguistic rules (the IF-THEN rules), and other parameters used for the classification task (e.g., the defuzzifier method).

Figure 2 and Figure 3 show the interface implemented to introduce Expert Knowledge and the FCL that results from these data. Once the data sent from the LMS is evaluated by the User's Learning Style Classification Service using this data included in the FCL, the classification data is sent to the Classification Results component to presents the results. Figure 4 shows all the components implemented and their interrelations.

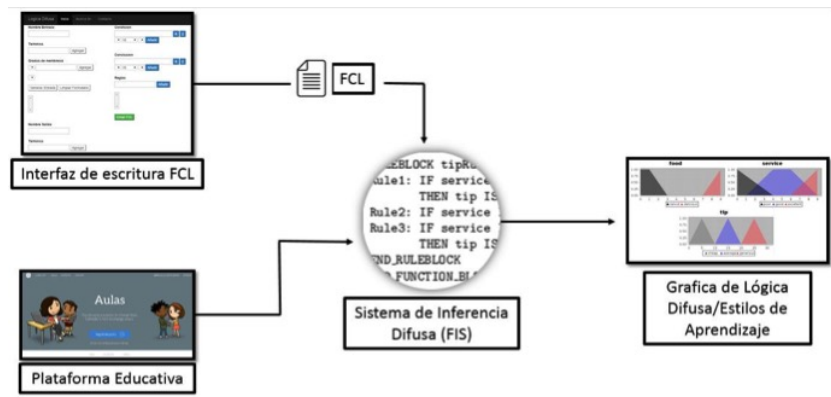

Fig. 4. A specific implementation for the proposed framework.

\section{Conclusions}

In this paper we presented a framework for automatic identification of learning styles in LMSs. We presented a specific implementation for the framework 
that takes advantage of existing LMSs, models of learning styles reported in psychology literature, and AI tools like fuzzy classification. The proposed implementation shows the validity of the framework from a technological perspective. As future work, we are planning to extend the framework implementation by including a learning mechanism in the classification phase as well as by including a second phase that deals with the automatic personalization of LMSs. Furthermore, the proposed framework must be validated by learners and teachers.

Acknowledgments. This work was partially funded by the SEP-PRODEP through the project ITSON-PTC-089.

\section{References}

1. Al-Zoube, M.: E-learning on the cloud. Int. Arab J. e-Technol. 1(2), 58-64 (2009)

2. Arnove, R.F.: Comparative education and world-systems analysis. Comparative Education Review pp. 48-62 (1980)

3. Cingolani, P., Alcala-Fdez, J.: jfuzzylogic: a robust and flexible fuzzy-logic inference system language implementation. In: FUZZ-IEEE. pp. 1-8. Citeseer (2012)

4. Dabbagh, N., Kitsantas, A.: Personal learning environments, social media, and selfregulated learning: A natural formula for connecting formal and informal learning. The Internet and higher education 15(1), 3-8 (2012)

5. Felder, R.M., Silverman, L.K.: Learning and teaching styles in engineering education. Engineering education 78(7), 674-681 (1988)

6. Felder, R.M., Soloman, B.A.: Learning styles and strategies. At URL: http://www. engr. ncsu. edu/learningstyles/ilsweb. html (2000)

7. Feldman, J., Monteserin, A., Amandi, A.: Automatic detection of learning styles: state of the art. Artificial Intelligence Review pp. 1-30 (2014)

8. Graf, S., Shuk, K., Liu, T.C.: Identifying learning styles in learning management systems by using indications from students' behaviour. In: Advanced Learning Technologies, 2008. ICALT'08. Eighth IEEE International Conference on. pp. 482486. IEEE (2008)

9. Hannafin, M.J., Hill, J.R., Land, S.M.: Student-centered learning and interactive multimedia: Status, issues, and implication. Contemporary Education 68(2), 94 (1997)

10. Kolb, A.Y., Kolb, D.A.: Learning styles and learning spaces: Enhancing experiential learning in higher education. Academy of management learning \& education 4(2), 193-212 (2005)

11. Latham, A., Crockett, K., McLean, D., Edmonds, B.: A conversational intelligent tutoring system to automatically predict learning styles. Computers \& Education 59(1), 95-109 (2012)

12. McNeill, F.M., Thro, E.: Fuzzy logic: a practical approach. Academic Press (2014)

13. Sandholtz, J.H., et al.: Teaching with technology: Creating student-centered classrooms. ERIC (1997)

14. Spring, J.: Education and the rise of the global economy. Routledge (1998)

15. Stephenson, J., Yorke, M.: Capability and quality in higher education. Routledge (2013)

16. Watson, W.R., Watson, S.L.: What are learning management systems, what are they not, and what should they become? TechTrends 51(2), 29 (2007) 
Ignacio Núñez, Márquez, Luis-Felipe Rodríguez, Guillermo Salazar Lugo, Luis A. Castro, et al.

17. Yueh, H.P., Hsu, S.: Designing a learning management system to support instruction. Communications of the ACM 51(4), 59-63 (2008) 